\title{
O conselho municipal de assistência social: um estudo de caso $^{1}$
}

\author{
The municipal council of social assistance: a case study
}

\author{
Marita Pereira Penariol* \\ Silvio José Benelli**
}

\section{Resumo:}

No presente artigo propõe-se, por meio de um estudo de caso, fazer uma análise crítica quanto à efetividade do Conselho Municipal de Assistência Social em um município de médio porte, localizado no interior do estado de São Paulo. Para tanto, foi realizado uma breve contextualização sobre os conselhos no Brasil e apresentação de um estudo de caso com a finalidade de problematizar os conselhos municipais de Assistência Social - enquanto um espaço de formulação, decisão, fiscalização e controle social da política pública de Assistência Social. Foi analisado seu funcionamento, efetividade e ressonâncias uma vez que se trata de um órgão de deliberação de novas ações do poder público no âmbito municipal no qual a sociedade civil possui influência significativa nas decisões tomadas. As análises apresentadas nesse trabalho evidenciam o modo como os conselhos municipais são reduzidos aos espaços de ordem burocrática nos quais as discussões não costumam ser politizadas, nem problematizam as ações, as omissões, o descaso e inclusive a negligência do poder público quanto às suas responsabilidades, não produzem efeitos diretos no próprio funcionamento da prefeitura, bem como em suas secretarias municipais, nas políticas públicas, nas estratégias, nos planejamentos e na execução dos programas.

Palavras-chave: Gestão Pública. Prefeitura. Política Pública de Assistência Social. Controle Social. Conselho Municipal de Assistência Social.

\begin{abstract}
:
In this article, we intend, through a case study, to make a critical analysis of the effectiveness of the Municipal Council of Social Assistance in a medium-sized municipality, located in the interior of the state of São Paulo. In order to do so, we made a brief context about the councils in Brazil and presented a case study with the purpose of problematizing the municipal councils of Social Assistance - as a space for formulation, decision, supervision and social control of public policy of Social Assistance, analyzing its functioning, effectiveness and resonances since it is a body for deliberation of new actions of the public power in the municipal scope in which the civil society has significant influence in the decisions taken. The analyzes presented in this paper show how municipal councils are reduced to bureaucratic spaces in which the discussions are not usually politicized, nor do they problematize the actions, omissions, neglect and even negligence of the public power over their responsibilities, do not produce direct effects on the city's own functioning, as well as on its municipal secretariats, public policies, strategies, planning and program execution.
\end{abstract}

Keywords: Public Management. City hall. Public Policy of Social Assistance. Social Control. Municipal Council of Social Assistance.

\footnotetext{
${ }^{1}$ Faz-se agradecimentos ao apoio financeiro da Coordenação de Aperfeiçoamento de Pessoal de Nível Superior (CAPES) para o desenvolvimento dessa pesquisa.

* Doutoranda e Mestre em Psicologia e Sociedade pela Faculdade de Ciências e Letras da Universidade Estadual Paulista (UNESP - Campus Assis). Graduada em Psicologia também pela UNESP, com ênfase em Políticas Públicas e Clínica Crítica e Subjetividade, Trabalho e Administração do Social. Professora colaboradora do Depto. de Pedagogia da Universidade Estadual do Centro-Oeste (UNICENTRO - Paraná).

** Psicólogo, mestre e doutor em Psicologia. Professor assistente doutor no Depto. de Psicologia Clínica e no Programa de Pós-Graduação em Psicologia da FCL/UNESP, Assis, SP.
} 


\section{Introdução}

O artigo é resultante de uma pesquisa de mestrado, cujo objetivo geral consistiu em compreender a dinâmica de funcionamento da gestão pública municipal em um município de médio porte do interior do estado de São Paulo. Especificamente, buscou-se compreender a história da formação cultural da política brasileira, por meio de uma revisão bibliográfica pertinente, a contextualizar à realidade pesquisada na história brasileira e poder analisar as modalidades de gestão adotadas naquela prefeitura, seus problemas e impasses. A partir dessa pesquisa de mestrado, considerou-se a intenção de contribuir com a elaboração de coordenadas e informações que possam servir de orientação para os trabalhadores que já atuam e também para os que eventualmente venham a ingressar no serviço público municipal, de modo que esses profissionais possam ter uma atuação mais avisada e precavida.

Para tanto, foi realizado uma pesquisa de campo, por meio da observação participante, em espaços institucionais da prefeitura municipal, com uma inserção efetiva nas atividades cotidianas e de rotina nas Secretarias Municipais de Governo e Administração, de Saúde e de Assistência Social. Durante essa imersão na Secretaria de Assistência Social, participou-se durante um ano das reuniões do Conselho Municipal de Assistência Social com a finalidade de se aproximar das discussões referentes à Política Pública de Assistência Social do município em questão. Nesse sentido, no presente artigo, pretende-se, por meio de um estudo de caso, fazer uma análise crítica quanto à efetividade do Conselho Municipal de Assistência Social enquanto um dispositivo de controle social e operacionalização da política pública de Assistência Social em um município de médio porte, localizado no interior do estado de São Paulo.

\section{Uma breve análise sobre os Conselhos Municipais no Brasil}

Os conselhos municipais são espaços públicos de composição plural e paritária entre Estado e sociedade civil, de caráter deliberativo e consultivo, com a finalidade de promover a participação da sociedade civil, juntamente com o poder público, na formulação, implementação e no controle das políticas públicas nas diversas esferas, sejam elas: Saúde, Assistência Social, Educação, Criança e Adolescente, Segurança etc. Portanto, os conselhos são o principal canal de participação popular nas três instâncias de governo - federal, estadual e municipal. Com relação à composição plural e paritária, os 
conselhos devem ser constituídos por um número par de conselheiros. Ao passo que para cada conselheiro oriundo do poder público, haverá um representante da sociedade civil. Logo, se um conselho contiver 10 conselheiros, deve haver 5 representantes do Estado e 5 da sociedade civil. Contudo, essa regra de paridade não se aplica aos Conselhos de Saúde e de Segurança Alimentar. Os primeiros são compostos por $25 \%$ de representantes de entidades governamentais, $25 \%$ de representantes de entidades não governamentais e 50\% de usuários dos serviços de saúde do Sistema Único de Saúde - SUS. Já os Conselhos de Segurança Alimentar são constituídos por $1 / 3$ de representantes governamentais, de áreas ligadas diretamente ao tema da segurança alimentar e $2 / 3$ da sociedade civil (BRASIL, 2011).

Os conselheiros municipais representantes do poder público devem ser nomeados pelo chefe do Poder Executivo - o prefeito - sendo imprescindível a articulação com os setores que desempenham ações voltadas às políticas sociais e econômicas, tais como a Assistência social, Saúde, Educação, Segurança, Trabalho e emprego, Segurança alimentar e nutricional, Administrativo-financeiro e outros. Desse modo, é importante que os Conselhos Municipais de Assistência Social realizem um trabalho em rede com os demais conselhos de políticas públicas no município já que muitas ações exigem uma atuação intersetorial (BENELLI, 2016a, 2016b; BENELLI; FERRI; FERREIRA JUNIOR, 2016).

A conquista da democracia participativa, por meio da Constituição Federal (CF) de 1988 (BRASIL, 1988), possibilitou à sociedade civil participar das decisões políticas, em diversos níveis. Portanto, não seria somente função do Estado o enfrentamento e a proposição de soluções para os problemas e demandas da população. Dessa forma, surgiram os Conselhos nas diversas áreas, tais como as da Saúde, da Assistência Social, da Educação, dos Direitos da Criança e do Adolescente, do Idoso, da Segurança, dentre outros, de maneira que o poder público e a sociedade civil, de modo paritário, ou seja, com o mesmo número de representantes titulares e de suplentes de cada categoria, pudessem trabalhar na formulação, na implementação, na gestão, no controle social e na avaliação das políticas públicas, nos níveis federal, estadual ou municipal. Os Conselhos representam uma forma de democracia direta e, portanto, uma inovação política em âmbito nacional (BRASIL, 2006a, 2007a, 2007b, 2010; ANHUCCI, 2007; ASSIS, 2009; BENELLI; COSTA-ROSA, 2012; CONSELHO MUNICIPAL DOS DIREITOS DA CRIANÇA E DO 
ADOLESCENTE, 2007). Tais conselhos ${ }^{2}$ foram criados para o controle da elaboração e implementação das políticas públicas, como resposta às pressões da sociedade civil para a redemocratização do País e aos movimentos populares de luta e defesa dos direitos humanos no Brasil, na década de 1980. Eles são um importante dispositivo de controle social, pois são espaços públicos onde a sociedade civil, juntamente com o poder público, pode exercer sua cidadania por meio do fortalecimento de sua participação democrática, além de aperfeiçoar a eficácia e a efetividade das políticas e dos serviços públicos.

Segundo o Conselho Nacional de Assistência Social (2013, p. 5),

\begin{abstract}
[...] "controle social ${ }^{3}$ é a participação da população na gestão pública, possibilitando aos cidadãos meios e canais de fiscalização e controle das instituições e organizações governamentais, de modo a verificar o bom andamento das decisões tomadas em seu nome. É o exercício de democratização da gestão pública, que permite à sociedade organizada intervir nas políticas públicas, interagindo com o Estado para a definição de prioridades e na elaboração dos planos de ação dos Municípios, Estados, Distrito Federal e da União. [...] Visa direcionar as políticas para o atendimento das necessidades prioritárias da população, melhorar os níveis de oferta e de qualidade dos serviços e fiscalizar a aplicação dos recursos públicos. Sua concepção está diretamente relacionada com o Estado de Direito, democracia, participação popular, partilha de decisões. Ou seja, trata-se de um Estado que esteja a serviço do interesse público onde os cidadãos possam exercer e reclamar seus direitos. Supõe a existência de espaços públicos onde a sociedade organizada possa exercer este controle sobre o Estado".
\end{abstract}

As bases legais dos conselhos municipais estão presentes na CF de 1988. Tal Constituição (BRASIL, 1988) definiu como diretrizes da política pública a descentralização político-administrativa, a participação popular na elaboração dessa política e o respectivo controle de suas ações em cada esfera da gestão. No entanto, é na lei orgânica municipal que consta o maior detalhamento e informações sobre os conselhos municipais, suas regulamentações, a quantidade prevista de conselhos na cidade e suas áreas de atuação. Além disso, cada conselho tem suas legislações específicas, bem como seu próprio regimento interno e estatuto, com as minúcias sobre seu funcionamento prático, descrição das reuniões, forma de eleição dos membros, duração do mandato e outras

\footnotetext{
2 Há uma vasta literatura que aborda o tema dos Conselhos. Para maior conhecimento sobre o assunto, recomenda-se buscar referências em Raichelis (1998), Gomes (2003), Gohn (2004, 2007, 2008), Brasil (2007), Amâncio, Dowbor e Serafim (2010), Conselho Federal de Psicologia (2010) e os estudos críticos de Anhucci (2007), Anhucci e Suguihiro (2010), Falchetti (2011), Benelli (2013), Benelli e Costa-Rosa (2012) e IBGE (2014).

${ }^{3}$ Sobre o conceito de controle social, recomenda-se ver: Campos (2004), Correia (2005, 2009), Machado (2012), Dantas (2013), Biasi (2016) e Brasil (2016). Para mais esclarecimentos sobre o tema do controle social, disponível em: http://www.deolhonolegislativo.com.br/ e http://www.votoconsciente.org.br/ para o acesso a métodos e cursos sobre o controle social no âmbito Legislativo.
} 
particularidades necessárias para seu andamento. Os conselhos são instituídos por meio de um projeto de lei municipal e cada conselho possui suas especificidades legislativas, que definem o número de conselheiros e suplentes, a estrutura organizacional, o período de vigência do mandato dos conselheiros, as atribuições, responsabilidades e competências e outras disposições gerais (BENELLI; COSTA-ROSA, 2012). No que se refere aos espaços de controle social, os conselhos gestores de políticas públicas, nas respectivas áreas e esferas, visam deliberar sobre a política pública, normatizar e regular a prestação de serviços públicos e privados e sua efetivação e aprovar propostas orçamentárias (BIASI, 2016).

No caso da Assistência Social, existe o Conselho Municipal de Assistência Social cujo aparato legal consta na Lei Orgânica de Assistência Social - LOAS (BRASIL, 1993), na Política Nacional de Assistência Social - PNAS (BRASIL, 2004) e na Norma Operacional Básica do Sistema Único de Assistência Social - NOBSUAS (BRASIL, 2005). De acordo com a LOAS (BRASIL, 1993), no parágrafo único do artigo 16, os conselhos de Assistência Social estão vinculados ao seu respectivo órgão gestor, o qual deve providenciar infraestrutura, garantindo recursos materiais, financeiros e humanos. Essas diversas normativas auxiliam a estruturação, o planejamento, a implantação, o monitoramento, a fiscalização e a avaliação dos serviços socioassistenciais presentes na Política Pública de Assistência Social.

\footnotetext{
A estratégia participativa do PNAS (2004) concentra-se na questão do "controle social" via "participação popular no processo de gestão político-administrativofinanceira e técnico operativa, com caráter democrático e descentralizado" (Brasil, 2004, p.49). Os principais mecanismos participativos previstos no novo desenho da política de assistência social são os Conselhos (FALCHETTI, 2011, p. 116).
}

Os conselhos municipais de Assistência Social têm como principais atribuições e competências no seu âmbito de atuação: deliberar e fiscalizar a execução da Política de Assistência Social e seu funcionamento; definir as prioridades e aprovar a Política Municipal de Assistência Social, em consonância com os princípios e diretrizes previstas na LOAS; convocar a cada dois anos a Conferência Municipal de Assistência Social, cujo propósito é avaliar a situação da Assistência Social no município e propor soluções para seu aperfeiçoamento, bem como encaminhar as deliberações; apreciar e aprovar o Plano da Assistência Social; analisar e aprovar o planejamento orçamentário dos recursos da assistência social a ser encaminhado ao Poder Legislativo; avaliar e aprovar a execução 
orçamentária e financeira do Fundo de Assistência a ser apresentada regularmente pelo gestor do Fundo; divulgar e promover a defesa dos direitos socioassistenciais; inscrever, acompanhar, avaliar e fiscalizar a rede socioassistencial do município - incluindo as entidades públicas e privadas de Assistência Social - bem como os serviços, programas, projetos socioassistenciais; elaborar critérios de qualidade para o funcionamento desses serviços no município; eleger entre seus membros a sua mesa diretora (presidente e vicepresidente paritariamente); elaborar e aprovar o seu regimento interno; fiscalizar e acompanhar o Benefício de Prestação Continuada - BPC e o Programa Bolsa Família - PBF; acompanhar a gestão integrada de serviços e benefícios socioassistenciais; e exercer o controle social da gestão do trabalho no âmbito do SUAS, conforme prescrito na NOBSUAS/RH (BRASIL, 2006b).

Há no Brasil uma lei em vigor desde 1996 que prevê a obrigatoriedade da criação de conselhos gestores municipais para o recebimento de recursos ao nível estadual e federal para as áreas sociais (Saúde, Educação, Assistência Social). Em decorrência dessa legislação, ocorreu uma expansão ${ }^{4}$ em mais de $40 \%$ no número de conselhos de acordo com Gohn (2007). No entanto, o aumento significativo de conselhos gestores não implica em seu funcionamento como um órgão de participação e controle social, de caráter deliberativo e descentralizado da gestão pública. A realidade de muitos municípios brasileiros ainda é a de conselhos consultivos, limitando sua atuação em aconselhamento, pesquisa de opiniões, sem poder efetivo de deliberação. Nesse sentido, Gohn (2007, p. 89) adverte para o fato de que nos

[...] municípios sem tradição organizativo-associativa, os conselhos têm sido apenas uma realidade jurídico-formal, e muitas vezes um instrumento a mais nas mãos dos prefeitos e das elites, falando em nome da comunidade, como seus representantes oficiais, não atendendo minimamente aos objetivos de se tornarem mecanismos de controle e fiscalização dos negócios públicos.

Com relação aos conselhos de Assistência Social no Brasil, o banco de dados da Pesquisa de Informações Básicas Estaduais - ESTADIC (IBGE, 2014, p. 103) relata que,

[...] todas as Unidades da Federação tinham Conselho de Assistência Social implantado (como em 2012), com caráter deliberativo e recursos orçamentários estaduais para apoiar o seu funcionamento. Cabe destacar que, em 2012, apenas o Estado do Acre informou não haver previsão de recursos específicos, em seu orçamento estadual, destinados à manutenção e funcionamento do

\footnotetext{
${ }^{4}$ Conforme os dados do IBGE (2001), mais de 90\% dos municípios tinham instituído conselhos municipais nas áreas de Assistência Social e Saúde e mais de 70\%, nas áreas de Educação e Direitos da Criança e do Adolescente.
} 
Conselho. Somente os Estados de Alagoas, Maranhão, Piauí, Rio Grande do Norte, Pernambuco e Paraná não tinham Conselhos de Assistência Social com caráter fiscalizador, e o Estado de Alagoas foi o único a declarar a não paridade do Conselho, sendo este composto, majoritariamente, por representantes do governo estadual.

A partir da contextualização realizada sobre os conselhos no Brasil, pretende-se nesse estudo de caso problematizar os conselhos municipais de Assistência Social enquanto um espaço de formulação, decisão e fiscalização da política pública de Assistência Social -, analisando seu funcionamento, efetividade e ressonâncias uma vez que se trata da deliberação de novas ações do poder público no âmbito municipal e que a sociedade civil possui influência significativa nas suas determinações.

\section{Conselho municipal de Assistência Social: um estudo de caso no interior do Estado de São Paulo}

Ao longo da pesquisa de campo do mestrado, mais especificamente nas visitas de observação participante na Secretaria de Assistência Social de um município de médio porte do interior do estado de São Paulo, participou-se durante 6 meses das reuniões e atividades de trabalho do conselho municipal de Assistência Social. O conselho municipal de Assistência Social, entre os anos de 2014-2015, era constituído por um total de 40 conselheiros, sendo 20 conselheiros oriundos do poder público e 20 representantes da sociedade civil, incluindo os titulares e seus respectivos suplentes. Com relação à quantidade de conselheiros, foi observado que havia uma paridade numérica, respeitando às exigências legais. Contudo, na prática, essa proporcionalidade não se cumpria tendo em vista a maior participação dos membros do poder público nas reuniões.

À vista disso, destaca-se alguns elementos importantes para o entendimento dos mecanismos de participação popular, controle social e também da máquina pública municipal. As reuniões ocorriam, em geral, em horário de trabalho, dificultando a participação do cidadão, sobretudo, de trabalhadores. Afinal, que empregador dispensaria seu funcionário para o comparecimento nessas reuniões, durante o horário de trabalho, e ainda mais para discutir sobre as políticas públicas no município? Em uma sociedade caracterizada pela ausência de tradição e experiência de participação política institucionalizada, torna-se complexa a cultura da participação política ativa e reivindicadora e de um modelo de gestão efetivamente democrático. Já para alguns 
funcionários do poder público, essas reuniões pareciam ser benquistas uma vez que eram consideradas como um intervalo durante o expediente de serviço.

No que diz respeito à paridade dos conselhos gestores, é preciso que haja igualdade não apenas numérica entre os representantes do poder público e da sociedade civil, mas uma equidade efetiva também no acesso às informações, suporte técnico e administrativo, conhecimento sobre o funcionamento da coisa pública e toda a linguagem tecnocrática que a permeia, disponibilidade de tempo para participação nas reuniões, no trabalho de fiscalização e demais atividades que envolvam a atuação dos conselheiros. Os membros advindos do poder público possuem maior domínio sobre as questões burocráticas da máquina pública, além de terem o respaldo salarial para desenvolverem suas atribuições como conselheiros no horário do seu expediente de trabalho haja vista que os conselheiros municipais não são remunerados para o desempenho de suas funções. Para isso, ressalta-se a real necessidade de realização de cursos e capacitações para os integrantes dos conselhos, de modo que eles tenham uma visão geral sobre política, gestão e administração pública, pois “a participação, para ser efetiva, precisa ser qualificada" (GOHN, 2007, p. 95).

No que se refere à participação, considerou-se fundamental o envolvimento dos usuários uma vez que eles contribuem para a garantia da produção de cidadania e do protagonismo social, viabiliza a apropriação do cidadão sobre assuntos relacionados à máquina pública, seus direitos e conquistas. Além dos usuários, foram mencionados os trabalhadores das políticas públicas como importantes atores institucionais da política, pois eles, inseridos no serviço público, podem ter um maior entendimento sobre a Política, "os processos e as condições de trabalho, seus desafios e potencialidades. Sua formação técnica e ética para o exercício político da participação, o torna um importante agente para assegurar, de um lado, a efetivação da política de garantia dos direitos" (BRASIL, 2016, p. 17).

As reuniões eram realizadas em uma sala do Centro de Referência Especializado de Assistência Social - CREAS, daquele município, uma vez que o espaço destinado às reuniões dos conselhos estava em reforma para ampliação. Em uma primeira participação, os pesquisadores, deste estudo, foram interrogados por alguns conselheiros sobre o motivo de estar naquele local e quem autorizou essa entrada. Tais questionamentos parecem contrariar o direito de participação popular, que é uma garantia constitucional, e 
o discurso oficial da gestão pública municipal de que qualquer cidadão pode exercer o controle social e participar ativamente dos conselhos. Em virtude destes não serem divulgados com frequência para que a população tenha conhecimento, muitas pessoas não sabem de sua existência e relevância. Somado a esse desconhecimento da população, a falta de uma cultura de participação nas decisões políticas também corrobora para o estranhamento por parte dos conselheiros quando alguém novato comparece às reuniões do conselho.

Portanto, vê-se que apesar de serem espaços onde a democracia, a descentralização e a horizontalidade deveriam prevalecer, há ainda um grande esforço a ser realizado visando superar a lógica autoritária, impositiva, verticalizada, hierárquica, centralizadora, patrimonialista, corporativista (BEHRING; BOSCHETTI, 2006), típicas da Administração Pública municipal. Desse modo, foi notado que a desinformação sobressai diante das práticas democráticas e transparentes (SUGUIHIRO, 2000).

[...] apesar de as formas de participação institucionalizadas (Conselhos) constituírem em importante instrumento de democratização no âmbito das políticas sociais, alterando o padrão tecnocrático e clientelista da relação Estado-sociedade, elas são limitadas diante do desafio enfrentado pela democracia no Brasil. As instâncias participativas enfrentam limites inerentes ao seu próprio escopo de ação, bem como enfrentam dificuldades colocadas pelas forças sociais que se contrapõem aos princípios democráticos e universais e inviabilizam uma maior participação popular na definição das ações estatais. Assinala-se, ainda, o risco de distorção dos mecanismos participativos quando estes se tornam instrumentos de gestão e perdem seu caráter político (FALCHETTI, 2011, p. 16-17).

As reuniões, habitualmente, eram iniciadas com a oração do "Pai Nosso", símbolo do cristianismo. Essa prática contraria o princípio de laicidade que prevê a imparcialidade do Estado perante aos assuntos religiosos, não defendendo ou discriminando qualquer religião. Dessa forma, observou-se de como o Estado laico não era respeitado naquele espaço de controle social no âmbito municipal. A grande maioria dos conselheiros eram adeptos da prática de oração, exceto uma das conselheiras que demonstrava certo descontentamento e permanecia em silêncio. Durante as visitas de observação participante, não houve um questionamento ou discussão sobre essa convenção, apenas seguia-se o ritual como de praxe. Essa prática religiosa traz para a reflexão a relação que ainda pode haver entre assistência e caridade.

Em geral, um dos principais impasses dos conselhos diz respeito à falta de organização e planejamento. A plenária do conselho parece estar sempre resolvendo 
questões emergenciais e pontuais, sem considerar as reais demandas do município no segmento que representa, além de haver conselheiros representantes de entidades municipais, colocando em risco os interesses coletivos (SUGUIHIRO, 2000).

\begin{abstract}
A participação popular no planejamento, gestão e controle, no setor da Saúde através dos Conselhos de Saúde, dos Conselhos de Cogestão dos dispositivos institucionais e das associações de "usuários" e familiares - visa e permite justamente a transformação do modo das relações intrainstitucionais na direção oposta ao funcionamento das instituições características do MCP: de heterogestão para cogestão e autogestão (COSTA-ROSA, 2013, p. 70).
\end{abstract}

As reuniões pareciam acontecer mais para o cumprimento da burocracia e do protocolo. Poucas decisões de relevância e que impactariam efetivamente na política pública de Assistência Social eram pensadas e discutidas nas reuniões do conselho municipal. Muitos dos conselheiros tinham pressa quanto ao encerramento da reunião, já que precisavam voltar para seus respectivos empregos, não compreendendo a devida importância e as verdadeiras funções daquele espaço. Observou-se ainda que muitas questões eram aprovadas sem maior exame pelos conselheiros e somente após a aprovação, havia um trabalho de acompanhamento e fiscalização. Nesse sentido, destacase com a necessidade de os conselhos possuírem assessoria jurídica, técnica, contábil, que deveria ser disponibilizada pela prefeitura, o que nem sempre acontece, para garantir a efetivação das políticas públicas de Assistência Social.

Sobre o processo eleitoral dos conselhos, foi observado que o poder público faz algumas indicações de funcionários para serem seus representantes em conselhos municipais e, em alguns casos, de modo estratégico, os nomeados não sabem nem ao menos qual é a finalidade de um conselho municipal, quais suas funções e importância, participando meramente para despachar documentos e cumprir com as burocracias emergenciais. Benelli e Costa-Rosa (2012, p. 582), em suas experiências de observação participante em dois conselhos municipais de um município de médio porte do estado de São Paulo, apontam que "os membros dos conselhos não pareciam ter consciência do seu lugar e papel no contexto sociopolítico municipal, mantendo uma atitude passiva, subserviente e descomprometida, quando não francamente aduladora dos gestores municipais". Para a gestão municipal é mais pertinente um conselho que opere apenas ao modo de "fachada", "de faz de conta", sem membros críticos e questionadores que dificultem as formas de atuação da prefeitura. Destaca-se ainda a estrutura dos próprios Conselhos, de "natureza setorial e fragmentada, pela qual cada Conselho fica limitado ao 
tema da política social a qual está vinculado e aos grupos que por ela têm interesse. Essa característica dos Conselhos não deixa de ser uma expressão da departamentalização da estrutura administrativa do Estado, cuja lógica de intervenção social é fragmentada (FALCHETTI, 2011, p. 126). E o notável é que o império romano já trabalhava com essa lógica: "divide e impera"!

No decorrer das reuniões do conselho municipal de Assistência Social, pode-se acompanhar o processo de votação para a eleição da nova gestão do conselho. A nomeação para a presidência e vice-presidência do conselho foi realizada apenas para cumprir a burocracia, pois houve a indicação de dois nomes para assumirem essas respectivas funções e ninguém se opôs. Os nomes indicados e aprovados para a diretoria do conselho eram de representantes de uma entidade assistencial particular e de um clube de serviços do Município, o que poderia dar margem para que os interesses desses estabelecimentos institucionais fossem privilegiados. Os participantes da reunião comentaram, com alívio, que, com as nomeações para preencher esses cargos "haviam se livrado da 'bucha'"'5. Com isso, essa experiência de imersão no campo da Assistência Social possibilitou verificar que as prefeituras criam os conselhos municipais conforme ordena a legislação, cumprindo com a formalidade legal. No entanto, raramente há um planejamento sistemático para o desenvolvimento das atividades dos conselhos, seu funcionamento fica reduzido a ser uma instância burocrática e as decisões, normalmente, são tomadas sem muitas reflexões e questionamentos, e "simplesmente sancionam tudo o que o Executivo determina, de modo cartorário e subordinado" (BENELLI, 2014, p. 201). Outra questão relaciona-se à alta rotatividade entre os conselheiros, pois os mandatos geralmente tem periodicidade bienal, prejudicando o funcionamento do conselho já que é preciso um tempo para aprender e assimilar as funções a serem desenvolvidas (BENELLI; COSTA-ROSA, 2012).

Durante a participação nas reuniões, foi presenciado ainda a posse da nova diretoria. Porém, a nomeação oficial não pode ocorrer no dia previsto em virtude da prefeitura não ter enviado a indicação de quatro representantes do poder público à composição do conselho._Essa atitude demonstra o descaso em que o próprio chefe do executivo lida com as políticas públicas de Assistência Social no município. O conselho municipal de Assistência Social é um órgão que reúne representantes do Estado e da

\footnotetext{
${ }^{5}$ O termo "bucha" foi empregado no sentido de uma tarefa árdua, cansativa, complexa e problemática.
} 
sociedade civil para discutir, estabelecer normas e fiscalizar a prestação de serviços socioassistenciais públicos e privados no Município. Portanto, sem a indicação de nomes para representar o governo, o trabalho do conselho fica estagnado, postergando ainda mais suas ações. Notou-se que muitos dos indicados como integrantes do conselho não possuem conhecimento algum sobre a temática e a complexidade que a envolve, mas são obrigados a frequentar as reuniões de modo a evitar conflitos com o prefeito, já que podem ser funcionários comissionados ou em função de confiança.

Os conselheiros precisam ser eleitos de modo democrático, ter conhecimento sobre o que significa sua representatividade frente aos interesses do coletivo e que saibam suas verdadeiras funções e atribuições, não devendo ser indicados para cumprir uma mera determinação jurídico-formal, com práticas executivas e reinvidicativas, de caráter imediatista e burocrático. Trata-se de fazer com que os conselhos funcionem para além do plano da aparência com a construção de um projeto político e social mais amplo (SUGUIHIRO, 2000).

As diretrizes básicas das políticas públicas devem ser decididas em espaços políticos, tais como os conselhos municipais, estaduais e federais e não centralizadas e "implementadas por burocratas enclausurados em seus gabinetes" (ANHUCCI, 2007, p. 74) e nos corredores das câmaras municipais de vereadores. Em uma das reuniões do conselho municipal de Assistência Social que se esteve presente, uma das conselheiras comentou que, segundo ela "seria melhor que estivéssemos na época da Ditadura Militar, assim não seria necessário que discutisse tudo isso. Sou burguesa e capitalista, não me preocupo e não gosto da ascensão da classe média". Esse discurso demonstra o desinteresse e a despreocupação da conselheira com as diretrizes, os caminhos possíveis e as ressonâncias com relação à Política de Assistência Social no município. Desse modo, observa-se que apesar dos conselhos serem um espaço potente, com possibilidades de transformação, inovação e efetivação das políticas públicas, a atuação dos conselheiros ainda se orienta por um lógica inversa, ou seja, pautada na filantropia e no assistencialismo, com olhar menos atento, crítico e politizado sobre a importância da cidadania, dos direitos e da democracia.

Com relação ao orçamento no campo da Assistência Social no município analisado, uma funcionária da Secretaria correspondente, membro do departamento de Monitoramento, realizou, durante uma das reuniões do conselho, uma apresentação 
referente ao ano de 2014, detalhando cada aplicação do dinheiro, sua origem e destinação. Todo o orçamento foi exposto de modo minucioso, por meio de um sistema online do governo estadual. Contudo, foi observado o desinteresse entre os presentes, quando o assunto consiste na prestação de contas, tabelas e dados numéricos. Houve muitas conversas paralelas, saidinhas durante a apresentação para atender o celular e olhares de insatisfação. A impressão vivenciada foi de que os presentes ficaram saturados depois de uma longa fala e nem queriam prorrogar a discussão, apenas aprovar e passar para o próximo item da pauta. Pois, o que todo aquele debate implicaria no andamento de suas vidas particulares? A maioria dos conselheiros, aparentemente, possuía condições de vida mais privilegiadas e não dependia dos serviços da Assistência Social.

Quando o assunto era orçamento público municipal, nem sempre as autoridades competentes - prefeito, secretário da Fazenda etc. - compareciam às reuniões, deixando as explicações a cargo dos próprios trabalhadores da Secretaria de Assistência Social. Em momentos específicos, como a aprovação do orçamento, um dos representantes do governo municipal apresentava-se no sentido de demonstrar os dados orçamentários e defender a atual gestão. A Secretaria de Governo e Administração teria verba de quase 6 milhões, correspondendo a 2,21\% do orçamento total do município. A Secretaria de Saúde de 69 milhões, equivalente a $25 \%$ do orçamento total do município. E a Assistência Social, 6 milhões, que corresponderia a 2,56\% do orçamento municipal. Sobre a Assistência, desses 6 milhões, 20\% (R\$1.300.000,00) destinava-se para a manutenção da secretaria. $\mathrm{Na}$ Constituição Federal de 1988 (BRASIL, 1988), obriga-se que no mínimo 15\% do orçamento sejam investidos na Saúde. Já na área da Assistência Social não há obrigatoriedade alguma sobre esse repasse, mas há uma luta entre os trabalhadores da Assistência para o repasse mínimo de 5\%. Foi observado que isso não ocorria no município e, no momento da aprovação do orçamento para o ano de 2015, ninguém questionou o pequeno valor desse repasse, nem perguntou se seria suficiente.

Apesar disso, o secretário da Fazenda disse que concordaria com algum aumento de verba para a Assistência Social, mas gostaria de saber de onde tirariam dinheiro para tanto. Concluiu ainda dizendo que não seria possível abrir e investir em nada novo, uma vez que o orçamento municipal já estava bastante comprometido com a manutenção da estrutura já existente. Por fim, todos se declararam favoráveis à proposta apresentada e 
foi encerrada a reunião. Sobre o planejamento e a destinação orçamentária no município, ressalta-se que:

O grau de priorização de uma política na gestão pública pode ser medido no modo pelo qual os recursos públicos são alocados no financiamento das ações, de modo que o acompanhamento da destinação orçamentária é fundamental e requer tenha havido planejamento das ações políticas (CONSELHO FEDERAL DE SERVIÇO SOCIAL, 2007, p. 21).

Essa experiência no Conselho Municipal de Assistência Social evidenciou que esses espaços de controle social estão reduzidos aos espaços de ordem burocrática nos quais as discussões não costumam ser politizadas, nem se problematizam as ações, as omissões, o descaso e inclusive a negligência do poder público quanto às suas responsabilidades. $E$ mais, não produzem efeitos diretos e instituintes no próprio funcionamento da prefeitura, bem como em suas secretarias municipais, nas políticas públicas, nas estratégias, nos planejamentos e na execução dos programas, que se orientassem pela implementação de direitos de cidadania para todos.

\section{Considerações Finais}

Apesar dos conselhos serem importantes espaços com grande potencial para o exercício da cidadania, construção, implementação, monitoramento e avaliação das políticas públicas e um organismo de controle social da gestão pública, é preciso que o próprio poder público se implique efetivamente, em uma perspectiva democrática. E mais,

\footnotetext{
A participação da sociedade civil nas novas esferas públicas - via conselhos e outras formas institucionalizadas - também comporta uma premissa básica: seu objetivo não é substituir o Estado, mas lutar para que este cumpra seu dever: propiciar serviços públicos com qualidade para todos (GOHN, 2008, p. 61).
}

Com relação ao funcionamento dos conselhos, Suguihiro (2000) revela que "embora o Conselho seja um colegiado criado a partir de exigências constitucionais, isto não tem lhe garantido a possibilidade de exercício pleno de suas funções e atribuições". Dessa forma, Gohn (2007, p. 108) descreve sobre os possíveis caminhos de atuação para os conselhos:

Os conselhos poderão ser tanto instrumentos valiosos para a constituição de uma gestão democrática e participativa, caracterizada por novos padrões de interação entre governo e sociedade em torno de políticas sociais setoriais, 
como poderão ser também estruturas burocráticas formais e/ou simples elos de transmissão de políticas sociais elaboradas por cúpulas, meras estruturas para transferência de parcos recursos para a comunidade, tendo o ônus de administrá-los; ou ainda instrumentos de acomodação dos conflitos e de integração dos indivíduos em esquema definidos previamente.

A Constituição Brasileira (BRASIL, 1988) promoveu um avanço ao instituir o Estado Democrático, com ênfase nos conceitos de democracia, participação popular, controle social e conselhos municipais. Todavia, a instauração legal e formal de um Estado Democrático, com a finalidade de garantir o exercício dos direitos sociais e individuais não assegura, instantaneamente, o usufruto desses direitos aos cidadãos. Dessa forma, é oportuno salientar a distinção entre a institucionalização formal e o gozo dos direitos uma vez que a Constituição assinala a existência de diversos direitos, porém é necessário que o sujeito labute por eles.

\begin{abstract}
Apesar da CF (BRASIL, 1988) estabelecer um amplo conjunto de direitos aos cidadãos brasileiros, sabemos que eles estão formalmente designados, no entanto, isso não é sinônimo de que eles são automaticamente incorporados à realidade, de modo que possam ser simplesmente gozados. Mesmo com alguns avanços conceituais importantes em termos da legislação brasileira, temos que reconhecer que ainda estamos em um processo de lutas para poder desfrutar dos direitos afiançados pela CF, já que o modelo capitalista de produção não é nada favorável aos direitos de cidadania para todos (PENARIOL; BENELLI, 2017, p. 107).
\end{abstract}

Finalmente, salienta-se a importância para que o cidadão reconheça os conselhos de direitos e outros espaços coletivos como lugares efetivos de lutas dos seus interesses e que, participando ativamente deles, possam fazê-los funcionar à altura de suas prerrogativas legais e institucionais, desempenhando verdadeiramente sua função política. Pois, do contrário, os conselhos funcionarão como espaços de transferência de funções do Estado para a sociedade, "operando num sentido mais gerencial e menos político, visando mais a eficiência administrativa e menos a participação deliberativa" (FALCHETTI, 2011, p. 12-13). Ressalta-se ainda à necessidade da publicização das informações e a transparência, "o fortalecimento do apoio técnico e financeiro do órgão gestor aos conselhos, a gestão do trabalho, a educação permanente e a articulação com outros conselhos de políticas, setoriais e de garantia de direitos" (BRASIL, 2016, p. 21) para o exercício efetivo do controle social por meio dos conselhos municipais.

\title{
Referências
}


AMÂNCIO, J. M.; DOWBOR, M.; SERAFIM, L. Controle social: dos serviços públicos à garantia de direitos. São Paulo: CEBRAP/ IDS, 2010.

ANHUCCI, V. O conselho municipal dos direitos da criança e do adolescente na perspectiva da participação e do controle social. 2007. 189f. Dissertação (Mestrado em Serviço Social e Política Social) - Universidade Estadual de Londrina, Londrina, 2007.

ANHUCCI, V.; SUGUIHIRO, V. L. T. A construção do Conselho Municipal dos Direitos da Criança e do Adolescente na perspectiva da participação e do controle social. Textos \& Contextos, Porto Alegre, v. 9, n. 1, p. 47-54, 2010.

ASSIS, S. G. (org.). Teoria e prática dos conselhos tutelares e conselhos dos direitos da criança e do adolescente. Rio de Janeiro: Fundação Oswaldo Cruz: Educação à Distância da Escola Nacional de Saúde Pública Sergio Arouca, 2009.

BEHRING, E. R.; BOSCHETTI, I. Política social: fundamentos e história. São Paulo: Cortez, 2006.

BENELLI, S. J. A construção de redes sociais: entre a conexão e a captura na gestão dos riscos sociais. In: BENELLI, S. J. $O$ atendimento socioassistencial para crianças e adolescentes: perspectivas contemporâneas. São Paulo: UNESP Digital, 2016a. p. 263-315.

BENELLI, S. J. A lógica da rede na atenção socioeducativa para crianças e adolescentes na Assistência Social. In: XAVIER, A. L. P.; GHAZIRI, S. M.; TEODORO, D. V S.; SILVA, P. C. T.; ZANIN, R. A. S. (org.). ECA, SUAS e o e o trabalho em rede de proteção à criança e ao adolescente. Rio de Janeiro: Publit, 2016b. p. 40-77.

BENELLI, S. J. Entidades assistenciais socioeducativas: a trama institucional. Petrópolis, RJ: Vozes, 2014.

BENELLI, S. J. Um psicólogo nos conselhos municipais de Assistência Social e dos direitos da criança e do adolescente: construindo referências para a prática. In: MATTIOLI, O. C.; ARAÚJO, M. F.; RESENDE, V. R. (org.). Violência e relações de gênero: o desafio das práticas institucionais. Curitiba: CRV, 2013. p. 115-144.

BENELLI, S. J.; COSTA-ROSA, A. Conselhos Municipais: prática e impasses no cenário contemporâneo. Psicologia em Estudo, Maringá, v. 17, n. 4, p. 577-586, 2012.

BENELLI, S. J.; FERRI, G. G.; FERREIRA JUNIOR, N. A modalidade de rede: discutindo suas origens e problematizando algumas de suas aplicações atuais. In: XAVIER, A. L. P.; GHAZIRI, S. M.; TEODORO, D. V S.; SILVA, P. C. T.; ZANIN, R. A. S. (org.). ECA, SUAS e o e o trabalho em rede de proteção à criança e ao adolescente. Rio de Janeiro: Publit, 2016. p. 152-197.

BIASI, L. M. F. Controle social. In: FERNANDES, R. M. C.; HELLMANN, A. (org.). Dicionário crítico: política de assistência social no Brasil. Porto Alegre: Editora UFRGS, 2016. p. 65-68.

BRASIL. [Constituição (1988)]. Constituição da República Federativa do Brasil. Brasília, DF: Senado Federal, 1988.

BRASIL. Cartilha SUAS 1: orientações acerca dos Conselhos e do controle social da política pública de Assistência Social. Brasília, DF: SNAS, 2007a. 
BRASIL. Como criar o conselho municipal de segurança alimentar e nutricional. Brasília, DF: Conselho Nacional de Segurança Alimentar e Nutricional, 2011.

BRASIL. Lei no 8.742/93. Lei Orgânica da Assistência Social. Brasília, DF: MDS, 1993.

BRASIL. Ministério do Desenvolvimento Social e Combate à Fome. Curso de introdução ao exercício do controle social do SUAS. Brasília, DF: MDS, 2016.

BRASIL. Norma Operacional Básica de Recursos Humanos da Assistência Social (NOB/RH). Brasília, DF: MDS, 2006b.

BRASIL. Norma Operacional Básica do Sistema Único de Assistência Social. Brasília, DF: SNAS, 2005.

BRASIL. Orientações gerais do Conselho Nacional de Assistência Social para a adequação da lei de criação dos conselhos às normativas vigentes e ao exercício do controle social no SUAS. Brasília, DF: Conselho Nacional de Assistência Social, 2010.

BRASIL. Orientações para Conselheiros da Área de Assistência Social. Brasília, DF: TCU, 2007b.

BRASIL. Política Nacional de Assistência Social. Brasília, DF: Ministério do Desenvolvimento Social e Combate à Fome, 2004.

BRASIL. Resolução $n^{\circ}$ 237, de 14 de dezembro de 2006. Diretrizes para a estruturação, reformulação e funcionamento dos Conselhos de Assistência Social. Brasília, DF: CNAS, 2006a.

CAMPOS, E. B. Controle Social das Políticas Públicas. Notas para Debate. Belo Horizonte, 2004.

CONSELHO FEDERAL DE PSICOLOGIA. Democracia e subjetividade: a produção social dos sujeitos democráticos. Brasília-DF: Conselho Federal de Psicologia, 2010.

CONSELHO FEDERAL DE SERVIÇO SOCIAL. Parâmetros para atuação de assistentes sociais e psicólogos(as) na Política de Assistência Social. Brasília, DF: CFESS, 2007.

CONSELHO MUNICIPAL DOS DIREITOS DA CRIANÇA E DO ADOLESCENTE. Orientações para criação e funcionamento. Brasília, DF: Pró-conselho Brasil, 2007.

CONSELHO NACIONAL DE ASSISTÊNCIA SOCIAL. Perguntas e respostas sobre funcionamento e estrutura dos conselhos de Assistência Social. Brasília, DF: CNAS, 2013.

CORREIA, M. V. C. Controle social. In: PEREIRA, I. B.; LIMA, J. C. F. (org.). Dicionário de educação profissional em saúde. 2. ed. Rio de Janeiro: EPSJV, 2009. p. 104-110.

CORREIA, M. V. C. Desafios para o controle social: subsídios para a capacitação de conselheiros. Rio de Janeiro: Editora Fiocruz, 2005.

COSTA-ROSA, A. Atenção psicossocial além da reforma psiquiátrica: contribuições a uma clínica crítica dos processos de subjetivação na saúde coletiva. São Paulo: Editora Unesp, 2013. 
DANTAS, H. (org.). De olho no legislativo: um método para acompanhar mandatos parlamentares. Rio de Janeiro: Fundação Konrad Adenauer, 2013.

FALCHETTI, C. Novos arranjos e velhos dilemas na democratização das políticas sociais: os conselhos de políticas públicas e a experiência de Araraquara. São Paulo: Cultura Acadêmica, 2011.

GOHN, M. G. Conselhos gestores e participação sociopolítica. 3. ed. São Paulo: Cortez, 2007.

GOHN, M. G. Empoderamento e participação da comunidade em políticas sociais. Saúde e Sociedade, São Paulo, SP, v. 13, n. 2, p. 20-31, 2004.

GOHN, M. G. O protagonismo da sociedade civil: movimentos sociais, ONGs e redes solidárias. 2. ed. São Paulo: Cortez, 2008.

GOMES, E. G. M. Conselhos gestores de políticas públicas: democracia, controle social e instituições. 2003. 110f. Dissertação (Mestrado em Administração Pública) - Escola de Administração de Empresas de São Paulo, Fundação Getúlio Vargas, São Paulo, 2003.

IBGE. Pesquisa de informações básicas estaduais: perfil dos Estados brasileiros. Rio de Janeiro: IBGE, 2014.

IBGE. Pesquisa de informações básicas municipais: perfil dos municípios brasileiros: 1999. Rio de Janeiro: IBGE, 2001.

MACHADO, L. M. O. Controle social da política de assistência social: caminhos e descaminhos. Porto Alegre: EDIPUCRS, 2012.

PENARIOL, M. P.; BENELLI, S. J. As interfaces entre a Psicologia e a Assistência Social. In: MATIOLLI, O. C.; ARAÚJO, M. F. (org.). Gênero, violência e psicologia: um percurso pelas políticas públicas. Curitiba: CRV, 2017. p. 97-111.

RAICHELIS, R. Esfera pública e Conselhos de Assistência Social: caminhos da construção democrática. São Paulo: Cortez, 1998.

SUGUIHIRO, V. L. T. Conselhos de direitos: caminho de sua consolidação. Serviço Social em Revista, Londrina, v. 3, n. 1, p. 9-26, jul./dez, 2000. Disponível em:

http://www.ssrevista.uel.br/c_v3n1_conselhos.htm. Acesso em: 5 dez. 2017. 